\title{
The gift of Taungs
}

\section{Andrew Hill}

Hominid Evolution: Past, Present and Future. Edited by P. V. Tobias.

Alan R. Liss:1985. Pp.499. \$38, £38.85.

Major Topics in Primate and Human Evolution. Edited by B. Wood, L. Martin and P. Andrews. Cambridge University Press:1986. Pp.364. £19.50, \$39.50.

Primate Evolution and Human Origins. Edited by R. L. Ciochon and J. G. Fleagle. Benjamin/Cummings:1986. Pp.396. \$31.95, £29.95.

ON THE face of it, a casual student of scientific methodology would find the basic principles of palaeoanthropology fairly easy to discern. They might be expressed as a few simple rules: every new fossil hominid specimen is the most important ever found and solves all known phylogenetic problems; every new hominid specimen is completely different from all previous ones, no matter how similar; every new hominid specimen is a new species, and probably new genus, and therefore deserves a new name. Although these precepts form a not too exaggerated characterization of procedure in the subject until quite recently, clearly the adoption of them is not likely to create the unambiguous truth about the issues they would address.

Not all claims can be uncritically discarded however, for some discoveries actually happen to be as important as their proud discoverers say they are. Consequently another, but less publicly conspicuous, aspect of palaeoanthropology is the evaluation of new material and the statements about it. Typically extravagant assertions surrounded the discovery in 1924 of a fossil juvenile skull from the Buxton Quarry at Taung in South Africa. Describing it as a human ancestor and "...one of the most significant finds ever made in the history of anthropology...the ultimate answer in the...study of the evolution of man", Raymond Dart named the curious specimen Australopithecus africanus. The predominantly British palaeoanthropological establishment, enthralled by Piltdown Man, said the thing was just an ape, nothing to do with the human lineage, and Nature hesitated before publishing $(\mathbf{1 1 5}, \mathbf{1 9 5})$. In fact, Dart turned out to be correct. The Taung baby formed a turning point in the study of human evolution.

The most obvious influence of this change, the subsequent attention on Africa, permeates all three of these books, but quite deliberately in Hominid Evolution: Past, Present and Future. Sixty years after the Taung discovery, Phillip Tobias, one much fascinated by anniversaries, organized a jubilee international symposium to celebrate the occasion. This volume is the result. Along with the other two books, it is a forceful and reassuring demonstration of the extent to which the subject has developed since then.

At least three areas of development seem prominent now, one being perennial. The treasure-hunting element of palaeoanthropology, with the attendant squabbles and hyperbole, may sometimes smack a little of non-science, but new fossils remain vitally important to the subject. They are the source of the biggest surprises and the greatest advances, and they need not be fossils of new species. Much of the anatomy of recognized species is relatively unknown, and fossils that illustrate previously unknown anatomy permit more refined phylogenetic and behavioural assessments to be made. Or they can be already known forms from new time periods or places. The many new discoveries of the past 60 years have resulted in major developments.

Second, progress has also been anade, which shows evidence of being more than fashion, in the analysis of these bones. This is largely due to cladistics. There are many who would not pursue committed cladists to the limits of their techniques and inferences; even so, they have adopted Hennigian terminology and principles as a valuable way of minimizing error. At the very least, cladistics forces workers to make explicit their taxonomic ideas, and clearly exposes the implications of different phylogenetic assertions. At this level alone it has made a significant contribution.

A third advance, as far as patterns of taxonomic branching are concerned, and to some extent the dating of them, has been the increasing refinement and acceptance of comparative molecular work on modern primates. Palaeontologists have realized, based largely on new fossils and the cladistic approach, that their ideas of early hominid divergence times were wrong, and that the more recent estimates suggested by molecular comparisons are more plausible.

Hominid Evolution contains over 50 papers which reflect these changes. They range from historical overviews of different aspects of the field, to treatments of particular anatomy of particular fossils and the details of different techniques. In time, the papers extend from the earliest higher primates to the origins of groups of modern humans. As may be expected of a large volume of such large scope, the result is a little patchy, with some articles admirable and others less so. But overall this is clearly an important publication, essential to all seriously concerned with the subject.

The books are not really to be regarded as alternatives - they have different origins and aims - but on balance I think Major Topics in Primate and Human Evolution a more interesting overview than Hominid Evolution. This also came from a recent conference, but one intentionally more focused. Delson (Nature 313,532 ) gives a summary of the presented papers. The subject is the relationships among taxonomic groups and the nature of divergence within the whole of primates. The sense of greater integration received from this book comes partly from this focus, and partly from the organizers' technique of inviting authors to review subjects not their prime speciality. A good example of this is a paper by Peter Andrews, who reviews the molecular evidence in a way that is highly accessible to others outside that field. An excellent article by Robert Martin, discussing the definition of primates, also includes a lucid and terse account of the benefits and limitations of cladistic thinking.

Primate Evolution and Human Origins also covers the whole of the primate order. Ciochon and Fleagle have collected papers on a broad range of issues, extending back over the past 25 years, though most are more current. Their choice was guided not by what is still correct, but by what has been influential, and this makes a very interesting and salutary package. The articles are arranged in groups in a useful way with short introductory essays from the editors. It is valuable to have such classic articles in one easily accessible place, but the book also highlights the direction that thinking, and sometimes misthinking, has taken. It is probably too much to hope that we will learn from our errors, but this latter aspect of the volume assists in the attempt.

Sir Peter Medawar, in a phrase ambiguously directed either to palaeoanthropology in general, or perhaps more understandably to Teilhard de Chardin's practice of it, once spoke of "a comparatively humble and unexacting kind of science". Such implied criticism could be justified; it has certainly been possible to get away with being an unexacting practitioner. But the aims are far from humble, and as these books well attest, the practice is becoming guided by a set of rules that are more exacting and rigorous than a casual student of scientific methodology might suspect.

Andrew Hill is in the Department of Anthropology, Yale University, PO Box 2114 Yale Station, New Haven, Connecticut 06520, USA. 